\title{
Studies on the Purification of Chlamydial Agents Grown in Yolk Sacs of Embryonated Eggs Using Disulphide-linked Immunosorbents and Enzymes
}

\author{
By I. S. SIM* AND J. STEPHEN \\ Department of Microbiology, University of Birmingham, Birmingham BI $52 T T$
}

(Received 18 September 1974; revised Io February 1975)

\begin{abstract}
SUMMARY
Immunosorbents were derived from avid and non-avid sera raised in rabbits to multiple or single injections of chlamydiae passaged once or three times in HeLa cells after routine passage in eggs. Egg-derived suspensions of chlamydiae required pretreatment before application to immunosorbent columns; this was most conveniently done by fractionation on Sepharose $4 \mathrm{~B}$. Immunosorbents derived from avid serum had greater capacity than those from non-avid sera. However, organisms were desorbed in low yield from an avid immunosorbent, but in higher yields from non-avid immunosorbents. Even under the best conditions, the immunosorbents yielded suspensions of organisms still contaminated with egg antigens.

Partially purified suspensions of chlamydiae were also treated with phospholipase $\mathrm{C}$ to yield suspensions of high purity.
\end{abstract}

\section{INTRODUCTION}

Several procedures have been used for purifying chlamydiae grown in the chorioallantoic or yolk sac membranes of embryonated eggs or in tissue culture cells. These include : centrifugation (Colón \& Moulder, I958; Jenkin, 1960); centrifugation with prior treatment with I M-KCl (Taverne, Blyth \& Reeve, 1964; Sowa et al. I969) or trypsin and celite (Weiss et al. I964); density gradient centrifugation as a main or terminal step (Tamura \& Higashi, I963; Vedros, 1967; Detels, Wang \& Grayston, 1968; Sarov \& Becker, 1968); DEAE-cellulose chromatography (Ormsbee \& Weiss, 1963; Katzenelson \& Bernkopf, 1965; Provost \& Vickers, 1972); liquid-liquid partition using fluorocarbons (e.g. Wang, Kenny \& Grayston, I967); fractional precipitation with ammonium sulphate (Wang et al. 1967); and, as a terminal step, use of antiserum to normal yolk sac antigens (Moulder \& Weiss, 195I). The techniques are often lengthy and may inactivate the agent, although for some purposes this is not important. It is difficult to extract exact information on the yields, infectivity and purity of 'purified' preparations from many of these papers.

We describe attempts to purify trachoma and inclusion conjunctivitis (TRIC) agent grown in yolk sac membrane, using disulphide-linked antibody immunosorbents (Stephen, Gallop \& Smith, 1966; Crook et al. 1972a). With other antigens this approach has shown high specificity (Stephen et al. 1966; Wood, Stephen \& Smith, 1968; Chidlow, Stephen \& Smith, 1970; Wood, Gould \& Smith, 1970) and has been used successfully to purify proteins (Crook, Stephen \& Smith, $1972 b$; Nicklin \& Stephen, 1974), vaccinia virus antigens (Birkbeck

* Present address: Department of Virology, Medical School, University of Birmingham, Birmingham B15 2 TJ. 
\& Stephen, 1970, 1971), bacterial toxins (Bird, Low \& Stephen, 1974), Semliki Forest virus (Wood et al. 1970) and influenza virus (Sweet, Stephen \& Smith, 1974). Yolk sac-grown agent is recognized as more difficult to purify than agent from allantoic fluid (Weiss et al. 1970), but we attempted to purify it because there are no suitable tissue culture systems for some TRIC strains, and eggs still offer the cheapest source of the large quantities of organisms as would be required for vaccine production (Collier, 1972).

\section{METHODS}

Chlamydiae. The agents used, followed by the abbreviations used in the text in parentheses, were as follows: TRIC/ /GB/MRC-4/ON (Jones, I96I) (MRC-4), and the fast-killing variant (MRC-4f) (Taverne et al. 1964); the fast-killing variant of TRIC/ /USA-Cal/CalI/OT (Hanna et al. 1959) (Bour f); guinea-pig inclusion conjunctivitis agent (Murray, I964) (gp-ic).

Growth of chlamydiae in eggs. Stocks of each agent were prepared by infecting six- to eight-day-old chick embryos (Tang et al. 1957) with a thousand $50 \%$ egg lethal doses $\left(\mathrm{ELD}_{50}\right) /$ egg. After approximately $50 \%$ of eggs had died the remaining live eggs were taken and $20 \%(\mathrm{w} / \mathrm{v})$ crude yolk sac homogenates made in phosphate buffered saline (Dulbecco \& Vogt, 1954) containing 0.25 M-sucrose.

Growth of MRC-4f in cells. HeLa cells (Wellcome Reagents Ltd) were grown in Eagles medium (Wellcome Reagents Ltd) with $10 \%$ (v/v) calf serum (Virology Department, University of Birmingham) and streptomycin $(500 \mu \mathrm{g} / \mathrm{ml})$. Confluent monolayers were infected with $\mathrm{KCl}$-fractionated $\mathrm{MRC}-4 \mathrm{f}$ (see below). The agent was allowed to adsorb on to cell monolayers for $4 \mathrm{~h}$ at $37^{\circ} \mathrm{C}$ in maintenance medium (Eagles medium with $2 \%, \mathrm{v} / \mathrm{v}$, heat-inactivated calf serum) after which fresh maintenance medium was added. The cells were harvested after $44 \mathrm{~h}$ and the agent released by ultrasonication (MSE ultrasonicator, $60 \mathrm{~W}, 3 \mathrm{~min}$ at $\left.0^{\circ} \mathrm{C}\right)$. The resultant suspension was centrifuged $\left(500 \mathrm{~g}\right.$ for $10 \mathrm{~min}$ at $4{ }^{\circ} \mathrm{C}$ ) and the supernatant collected. The TRIC agent (designated once-passaged HeLa cell-grown MRC-4f) was used for immunizing rabbits directly or after two further passages through HeLa cells.

Measurement of infectivity. Suspensions of MRC-4f were assayed in eggs or HeLa cells (Reeve \& Taverne, 1967).

Measurement of chlamydial particle concentration. This was determined by dark-field microscopy (Reeve \& Taverne, 1962). The coefficient of variation of particle counts was estimated for a number of suspensions and was never greater than $15 \%$.

Antisera. Avid (and non-avid, as defined by Nicklin \& Stephen, 1973) anti-TRIC antisera were raised in rabbits by three or four subcutaneous injections of live MRC-4f which had been once passaged in HeLa cells (approx. $10^{7} \mathrm{ELD}_{50}$ per injection). The agent was given in complete Freund's adjuvant at not less than weekly intervals followed by an intravenous boost of live agent $\left(10^{7} \mathrm{ELD}_{50}\right)$ without adjuvant at least 40 days after the final subcutaneous injections. Rabbits were bled Io days thereafter.

Non-avid anti-TRIC antisera were obtained from rabbits after a single injection of live MRC-4f as above; the latter had been passaged once or three times through HeLa cells. Rabbits were bled Io days after injection.

Rabbits were also immunized with antigen-antibody complexes following the schedule of Birkbeck \& Stephen (197I). Immune aggregates were prepared in immunodiffusion gels (Watson \& Wildy, 1969) using soluble antigens derived from egg-grown MRC-4f and avid anti-TRIC antisera which contained no detectable anti-egg antibodies either at the outset or after adsorption with normal yolk sac antigens. 
Anti-egg antisera were raised in rabbits by multiple subcutaneous injections of $5 \mathrm{mg}$ amounts of normal yolk sac antigens in complete Freund's adjuvant on days 0, 2, 4 and 9 and intravenous injections of 100,200 and $200 \mu \mathrm{g}$ of normal yolk sac antigens without adjuvant on days 47, 49 and 5I, respectively. Rabbits were bled on days 6I and 62 .

$\gamma$-Globulin concentrates of immune sera were prepared by $\mathrm{Na}_{2} \mathrm{SO}_{4}$ precipitation (Smith et al. 1962) and used throughout this work, but are referred to as antisera, for brevity.

Immunodiffusion. The method of Crowle (I958) was used. Soluble antigens from chlamydiae were obtained by ultrasonication (MSE ultrasonicator, $60 \mathrm{~W}$, $10 \mathrm{~min}$ at $0^{\circ} \mathrm{C}$ ) of suspensions of $\mathrm{KCl}$-fractionated organisms ( $\mathrm{I}^{10}$ particles $/ \mathrm{ml}$ ). Normal yolk sac antigens were prepared from uninfected 14 -day-old yolk sacs subjected to a single cycle of differential centrifugation and ultrasonication.

Infectivity of $M R C-4 f$ after exposure to various $p H$ buffers. $\mathrm{KCl}$-fractionated MRC-4f was diluted $\mathrm{I}: \mathrm{IO0}$ in the appropriate buffer, incubated for $\mathrm{I} \mathrm{h}$ at $5{ }^{\circ} \mathrm{C}$ and immediately titrated in eggs. The buffers $(I 0 \cdot 26)$ used were citrate buffers $\mathrm{pH}_{3 \cdot 0,} 4^{\circ} 0$ and 5.3 , phosphate buffers $\mathrm{pH} 6.0$ and 8.0 , borate buffers $\mathrm{pH} 9.0$ and 10.0 (compositions as given by Nicklin \& Stephen, 1973), and glycine- $\mathrm{NaOH}-\mathrm{NaCl}, \mathrm{pH}$ I0.5 and I I.0 (compositions as given by Miller \& Golder, 1950). A similar method was applied for determining the effect of $\mathrm{pH}$ on particle integrity.

Preparation and use of disulphide-linked immunosorbents. Immunosorbent polymers were prepared by thiolating $\gamma$-globulin concentrates, precipitating the thiolated protein with $\mathrm{Na}_{2} \mathrm{SO}_{4}$ (as above) and cross-linking the pellet of thiolated protein with potassium ferricyanide (modification I procedure, Crook et al. 1972a). Columns (Mark III-type, Crook et $a l$. $1972 b$ ) were prepared by placing a mixture of -S-S-linked immunosorbent and Sephadex G-I 5 on top of more Sephadex G-I5; the column was equilibrated in phosphatebuffered saline (PBS), containing (g/l): $\mathrm{Na}_{2} \mathrm{HPO}_{4}, 8 \cdot 09 ; \mathrm{KH}_{2} \mathrm{PO}_{4}, 2.44 ; \mathrm{NaCl}, 15 \cdot 9$. This arrangement allows the use of extreme acidic (or alkaline) pH-buffers in desorbing labile antigens from homologous immunosorbent and recovering them in neutral buffer after only brief exposure to the potentially denaturing desorbent (Crook et al. I972b). Buffers used in this work were PBS for adsorbing agent, and either $0.2 \mathrm{M}$-glycine adjusted to $\mathrm{pH} 10.5$ with $\mathrm{NaOH}$ or $0.2 \mathrm{M}$-arginine adjusted to $\mathrm{pH}$ I I 3 with $\mathrm{HCl}$ for desorbing TRIC agent.

For some experiments a batch procedure (Sweet et al. 1974) was used. Immunosorbent polymer was stirred with TRIC agent suspension for $3 \mathrm{~h}$ at $4{ }^{\circ} \mathrm{C}$, centrifuged $(500 \mathrm{~g}$ for Io min at $4{ }^{\circ} \mathrm{C}$ ) and the supernatant withdrawn. The immunosorbent was washed with at least five $5 \mathrm{ml}$ volumes of PBS and desorbed with at least three $5 \mathrm{ml}$ volumes of the appropriate buffer.

Immunosorbents, either in column or batch procedure, could be recycled several times. After desorption, immunosorbent was re-equilibrated in PBS and the adsorption-desorption procedure repeated.

Preliminary purification of $M R C-4 f$. It was usually necessary to effect some preliminary purification of chlamydiae obtained as homogenates of infected yolk sac membranes. Four methods were used: (i) $\mathrm{KCl}$ fractionation. An equal volume of $2 \mathrm{M}-\mathrm{KCl}$ at o ${ }^{\circ} \mathrm{C}$ was added slowly to egg-derived TRIC agent suspension (Taverne et al. 1964) and centrifuged (I $2000 \mathrm{~g}$ for 20 min at $4{ }^{\circ} \mathrm{C}$ ). The pellet was resuspended in PBS containing sucrose and centrifuged ( $500 \mathrm{~g}$ for Io min at $4{ }^{\circ} \mathrm{C}$ ). The supernatant was collected and the two centrifuging procedures repeated. The final supernatant was designated $\mathrm{KCl}$-fractionated MRC-4f. (ii) Modified $\mathrm{KCl}$ fractionation. Homogenates of MRC-4f were subjected to the first two centrifugal steps described above. The pellet thus obtained was suspended in borate-buffered saline $\mathrm{pH} 7 \cdot 3$ (72.3 $\mathrm{g} \mathrm{Na}_{2} \mathrm{~B}_{4} \mathrm{O}_{7} \cdot \mathrm{IOH}_{2} \mathrm{O}, 5 \cdot 84 \mathrm{~g} \mathrm{NaCl} / 1 ; \mathrm{pH}$ adjusted to $7 \cdot 3$ with conc. $\left.\mathrm{HCl}\right)$ containing 
$\mathrm{CaCl}_{2}$ (final concn $0.05 \%, \mathrm{w} / \mathrm{v}$ ). The organisms were centrifuged and finally resuspended in borate-buffered saline. The product was designated modified $\mathrm{KCl}$-fractionated MRC-4f. (iii) Trypsin-celite fractionation. Crude yolk sac homogenates were adjusted to pH 7.5 and treated with trypsin $\left(0.2 \%\right.$, w/v, for 15 min at $37^{\circ} \mathrm{C}$ ) (Wang \& Grayston, 1967). An equal volume of $2 \mathrm{M}-\mathrm{KCl}$ was added and the suspension centrifuged ( $12000 \mathrm{~g}$ for $20 \mathrm{~min}$ at $4{ }^{\circ} \mathrm{C}$ ). The pellet was resuspended in PBS containing sucrose, and celite added ( $0 \cdot \mathrm{I} \mathrm{g}$ celite/g original yolk sacs). After about $5 \mathrm{~min}$ the celite was removed with the flocculated protein by centrifugation ( $500 \mathrm{~g}$ for $10 \mathrm{~min}$ at $4{ }^{\circ} \mathrm{C}$ ). The TRIC agent was pelleted again and resuspended in PBS containing sucrose to the desired volume. The product was designated trypsin-celite-fractionated MRC-4f. (iv) Sepharose $4 \mathrm{~B}$ fractionation. Crude yolk sac homogenates were fractionated on columns of Sepharose 4B (Pharmacia) equilibrated in PBS. Up to $50 \%$ of the applied TRIC agent was recovered in the breakthrough peak. This peak also contained approx. $50 \%$ of the applied protein. Several other fractions (containing no TRIC particles) were obtained from the column and some material was strongly adsorbed to the Sepharose.

Purification of $M R C-4 f$ using phospholipase $C$. The source of crude enzyme was a Clostridium welchii type A freeze-dried culture filtrate, lot ADro43D2, a gift from Dr R. O. Thomson, Wellcome Research Laboratories; it contained ig LV units of $\alpha$-toxin/mg, where I LV unit is that amount of toxin which in the presence of $I$ i.u. antitoxin will cause a turbid reaction in egg yolk. Excess substrate present in crude yolk sac homogenates of MRC-4f was removed by modified $\mathrm{KCl}$ fractionation of $\mathrm{MRC}-4 \mathrm{f}$. Suspensions were incubated at $37^{\circ} \mathrm{C}$ with phospholipase (particle to enzyme ratios were varied) for the times indicated and immediately chilled to $0{ }^{\circ} \mathrm{C}$. During overnight storage, visible gel-like aggregates of material formed which were separated from the TRIC agent suspension by rapid filtration through approx. I $\mathrm{ml}$ Sephadex G-I5. The MRC-4f suspension was centrifuged ( $12000 \mathrm{~g}$ for 30 min at $4{ }^{\circ} \mathrm{C}$ ), resuspended in borate-buffered saline, and analysed for total particles, nitrogen, lipid phosphorus and dry weight.

Estimation of purity of $M R C-4 f$. The purity of $M R C-4 f$ preparations was assessed by total particle counts, total nitrogen analysis (by micro-Kjeldahl digestion followed by direct Nesslerization), by lipid phosphorus analysis [lipid extraction (Bligh \& Dyer, 1959) followed by phosphate determination (Bartlett, 1959)] and dry weight determination. Guinea-pig hypersensitivity tests (Hughes et al. 1974) were used to detect normal yolk sac antigens and normal rabbit serum proteins in MRC-4f preparations.

\section{RESULTS}

\section{Production of antisera}

The rationale for raising the antisera was as follows: To isolate, by immunosorbents, MRC-4f from egg yolk sacs required antisera containing antibodies to MRC-4f antigens but not to egg antigens. This involved the use of a second host (HeLa cells) for growing the organism. Thus, rabbits immunized with MRC-4f grown in HeLa cells should contain antibodies to MRC-4f and to HeLa cell antigens but not to egg antigens. Alternatively, the requirement for the two-host system could be overcome by using antigen-antibody complexes isolated from immunodiffusion gel media and injecting these into rabbits. Here the specificity of the resultant antisera should depend only on the degree to which the isolated immune-complex was contaminated with other antigens in the immunodiffusion-gel.

Production of antiserum against MRC-4f grown in HeLa cells. Avid antisera raised in rabbits by multiple injections of $\mathrm{MRC}-4 \mathrm{f}$ passaged once in $\mathrm{HeLa}$ cells were analysed by 

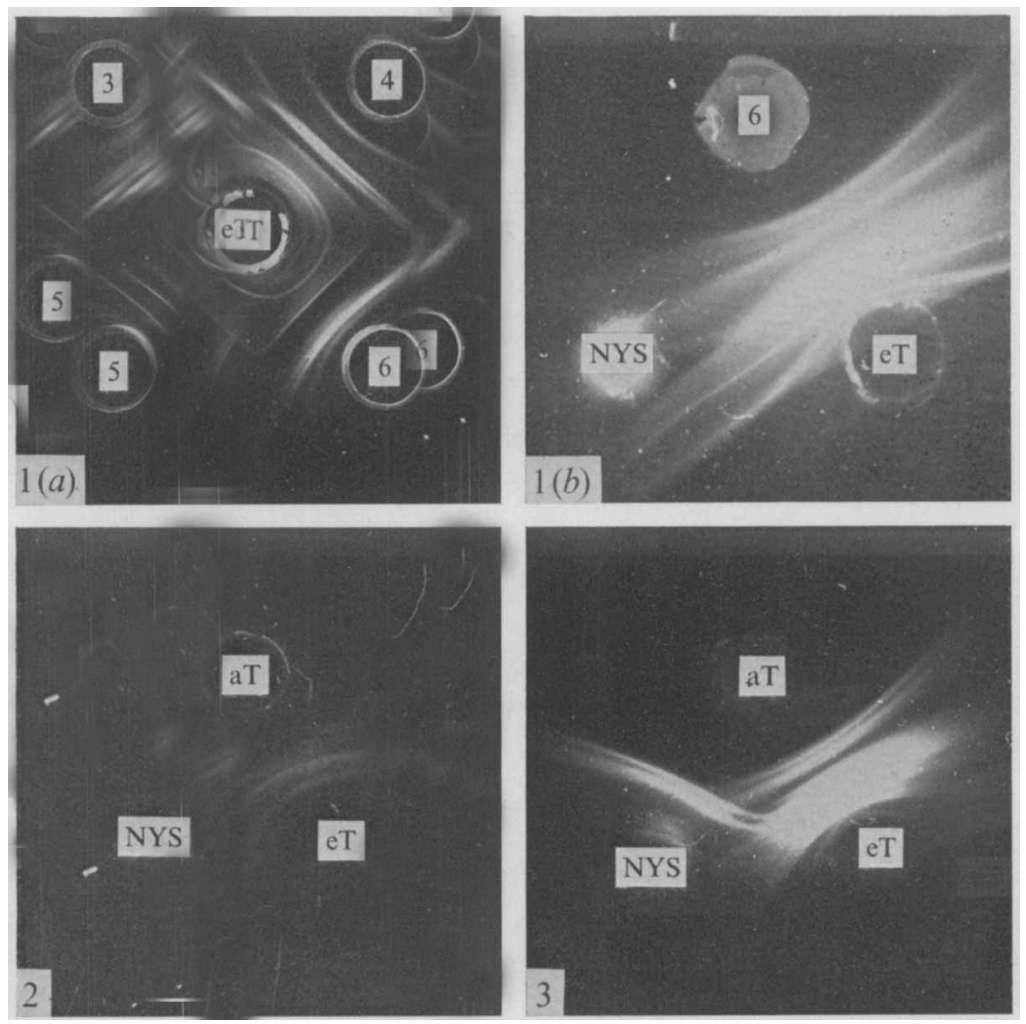

eT, soluble antigens derived from yolk sac-grown MRC-4f; NYS, normal yolk sac antigens.

Fig. I $(a)$ and $(b)$. Immunodiffusion analyses of avid anti-Hela cell-grown MRC-4f antisera from individual rabbits $(3,4,5$ and 6$)$.

Fig. 2. Immunodiffusion analysis of non-avid sera (aT) raised in rabbits in response to thricepassaged HeLa cell-grown MRC-4f.

Fig. 3. Immunodiffusion analysis of an antiserum (aT) raised in a rabbit by injection of antigenantibody complexes.

micro-immunodiffusion. Individual sera showed up to seven precipitins (Fig. I a) with no evidence of precipitating anti-egg antibodies (Fig. $\mathrm{I} b$ ). Non-avid antisera showed fewer precipitins, and in one instance detectable anti-egg antibodies; the presence of the latter was attributed to egg antigens in some preparations of $\mathrm{MRC}-4 \mathrm{f}$ which had been passaged once in HeLa cells before being used to immunize the rabbits. In further experiments, to ensure complete removal of contaminating egg antigens, MRC-4f was passaged three times through $\mathrm{HeLa}$ cells and used to raise non-avid sera in a separate group of rabbits. These resultant antisera showed no precipitating anti-egg antibodies but four TRIC-specific precipitins were detected (Fig. 2); no egg antigens were detected in the preparations of MRC-4f passaged three times in HeLa cells.

Production of antiserum against immune complexes. An attempt was made to avoid multiple passage of the agent through a second host by immunizing rabbits with MRC-4f-specific immune complexes. Rabbits were immunized with antigen-antibody complexes prepared from egg-derived MRC-4f antigens and an avid serum raised to MRC-4f grown in HeLa cells and which contained no detectable precipitating anti-egg antibodies. However, the 


\section{Table I. Recovery of $M R C$-4f from disulphide-linked polymers derived from unrelated $\gamma$-globulin}

$\mathrm{KCl}$-fractionated MRC-4f was added to three batches of polymer (total protein of each, $60 \mathrm{mg}$ ) and the amounts of TRIC agent recovered unadsorbed were determined by total particle counts. Batch I was washed with $0.2 \mathrm{M}$-glycine- $\mathrm{NaOH}$ buffer, pH 10.5 , after cycle 1 and re-equilibrated in PBS before cycle 2 .

\begin{tabular}{|c|c|c|c|c|}
\hline & & & $M R C-4 f$ & \\
\hline & & Tota & rticles & \\
\hline Batch & Cycle & Applied & $\begin{array}{l}\text { Recovered } \\
\text { unadsorbed }\end{array}$ & $\begin{array}{l}\text { of applied } \\
\text { recovered }\end{array}$ \\
\hline I & I & $7.4 \times 10^{9}$ & $6.3 \times 10^{9}$ & 85 \\
\hline & 2 & $1.0 \times 10^{10}$ & $8.2 \times 10^{9}$ & 82 \\
\hline 2 & I & $8.3 \times 10^{9}$ & $6.6 \times 10^{9}$ & 80 \\
\hline 3 & I & $8.3 \times 10^{8}$ & $9.5 \times 10^{8}$ & 116 \\
\hline
\end{tabular}

resultant antisera contained both TRIC-specific and egg-specific precipitins (Fig. 3); preimmune sera showed no precipitating activity in immunodiffusion tests against normal yolk sac antigens.

\section{Infectivity of $M R C-4$ f after exposure to various $p H$ buffers}

Over a period of $\mathrm{I} h$ at $5{ }^{\circ} \mathrm{C}$ the agent was stable in buffers of $\mathrm{pH}$ values 6.0 to $10 \cdot 0$. Above pH 10.0 and below pH 6.0 significant losses of infective agent were recorded; the losses were greater on the acid than on the alkaline side. Initially a $0.2 \mathrm{M}$-glycine-NaOH buffer, $\mathrm{pH}$ 10.5, was selected for desorption, since this was the limiting $\mathrm{pH}$ at which the agent remained infective and the number of particles recovered was high ( $98 \%$, after I h). Desorption was later done with a $0 \cdot 2 \mathrm{M}$-arginine- $\mathrm{HCl}$ buffer, $\mathrm{pH}$ I I $\cdot 3$, although this caused apparent disruption of the particles in the $\mathrm{pH}$ stability tests; only i I \% of particles were recovered after $5 \mathrm{~min}$ and none was detectable by total particle assay after $\mathrm{I} \mathrm{h}$ at $5{ }^{\circ} \mathrm{C}$.

\section{Purification of $M R C-4$ using immunosorbents}

Specificity of disulphide-linked polymers. At high doses [from $7 \times 10^{9}$ to $\mathrm{I} \times 10^{10}$ particles (batch I, cycles I and 2; batch 2, cycle I)] the amount of TRIC agent recovered unadsorbed at $\mathrm{pH} 7 \cdot 0$ from polymers derived from unrelated $\gamma$-globulin was not significantly different from the amount applied, i.e. there appeared to be little or no non-specific adsorption of the agent (Table I), although, because of the limitations of the total particle count assay it was possible that up to $3 \times 10^{9}$ particles were retained in the polymer. However, when the third batch of polymer was loaded with approximately one-tenth the amount of MRC-4f used previously, again a high yield of particles was recovered (batch 3, cycle I; Table I).

The recovery of unadsorbed egg antigens was not measurable. However, if egg antigens were adsorbed at $\mathrm{pH} 7 \cdot 0$, they were not desorbed (as judged by immunodiffusion tests) when the polymers were washed with $0 \cdot 2 \mathrm{M}$-arginine- $\mathrm{HCl}$ buffer, $\mathrm{pH}$ i I 3 .

Purification of $M R C-4 f$ using anti-TRIC immunosorbents derived from avid antisera. Two samples of disulphide-linked immunosorbent polymer were prepared from avid antiMRC-4f sera pooled from several rabbits and were used in batch and column procedures. Each polymer was loaded with $\mathrm{KCl}$-fractionated MRC-4f, washed with $\mathrm{PBS}$, and desorbed with $0.2 \mathrm{M}$-glycine- $\mathrm{NaOH}$ buffer, $\mathrm{pH}$ 10.5; in all, 5 cycles were carried out. The polymer 


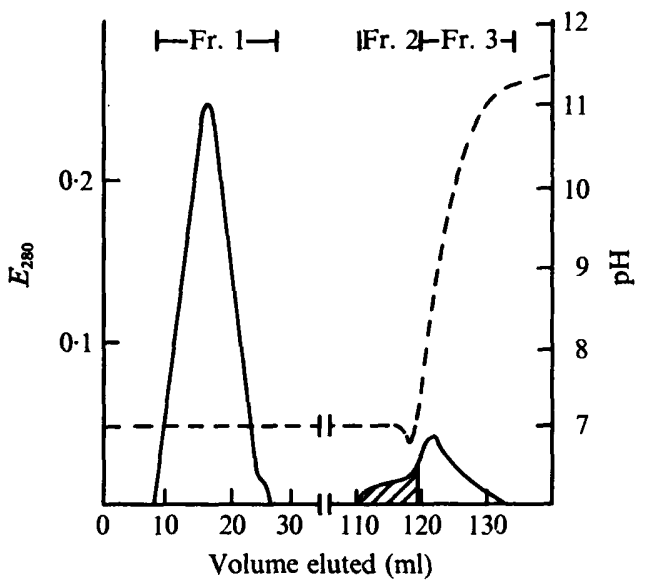

Fig. 4

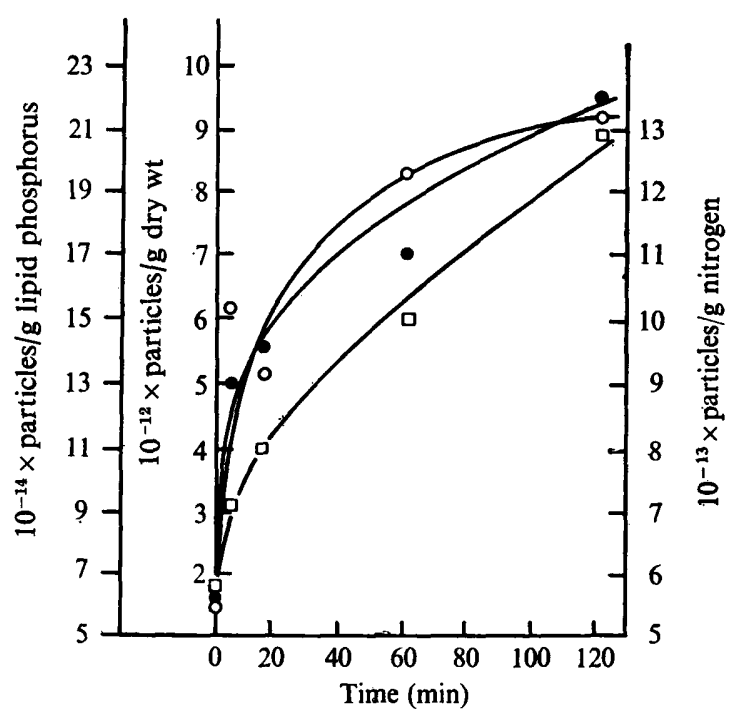

Fig. 5

Fig. 4. Immunosorbent fractionation of trypsin-celite fractionated MRC-4f. The immunosorbent was derived from a non-avid serum raised to once passaged HeLa cell-grown MRC-4f and contained $30 \mathrm{mg}$ polymer. The column was loaded with $2.1 \times 10^{9}$ particles. Fraction I (Fr. I) is the unadsorbed material ( $54 \%$ of the applied TRIC agent); the neutral fraction (Fr. 2) contains the desorbed MRC-4f ( $33 \%$ of the adsorbed agent); no particles were observed in the alkaline fraction (Fr. 3). Later experiments (see text) suggested that the material in Fr. 3 was of egg origin and was bound by the Sephadex G-15. -,$E_{280} ;---, \mathrm{pH} ; \mathbb{Z}$, neutral desorbed fraction.

Fig. 5. Effect of incubation of partially purified suspensions of MRC-4f with phospholipase C on the ratios particles:dryweight, particles:lipid phosphorus and particles:nitrogen. $\bigcirc$, Total particles/g dry wt; $\bigcirc$, total particles/g lipid phosphorus; $\square$, total particles/g nitrogen.

adsorbed approximately $3 \times 10^{8}$ particles of $\mathrm{MRC}-4 \mathrm{f} / \mathrm{mg}$ polymer protein, but the amount of MRC-4f desorbed was only about $4 \%$ of that adsorbed.

Purification of $M R C-4 f$ using anti-TRIC immunosorbents derived from non-avid antisera raised to MRC-4f passaged once through HeLa cells. In an attempt to desorb the agent in higher yield, non-avid immunosorbents were investigated. Two polymers were prepared from different non-avid antisera and packed in columns. These were loaded with trypsincelite-fractionated MRC-4f and washed with PBS. Desorption with $0.2 \mathrm{M}$-glycine-NaOH buffer, $\mathrm{pH}$ 10.5, gave better but variable yields of particles than had been obtained from avid immunosorbents. More consistent yields were obtained when columns of similar capacities were desorbed with $0.2 \mathrm{M}$-arginine- $\mathrm{HCl}$ buffer, $\mathrm{pH} \mathrm{II} \cdot 3$. Thirty $\mathrm{mg}$ of polymer adsorbed $5.5 \times 10^{8}$ particles (mean of 8 runs). Desorption with $0.2 \mathrm{M}$-arginine- $\mathrm{HCl}$ buffer, $\mathrm{pH}$ I $\mathrm{I} \cdot 3$, yielded $35 \%$ of adsorbed particles in the neutral $\mathrm{pH}$ fraction (see Fig. 4 for a typical elution profile with this type of starting material). Columns were recycled eight times without apparent loss of capacity or decrease in the yield of agent desorbed.

Particle to ELD ${ }_{50}$ ratios of II9: I and I60:I were obtained before and after immunopurification, respectively; in a separate experiment the respective ratios were $110: 1$ and 80: I. This indicates little or no inactivation of $\mathrm{MRC}-4 \mathrm{f}$ during the procedure.

Suspensions of immunopurified MRC-4f dialysed against PBS to remove traces of arginine buffer contained from $2.4 \times 1 \mathrm{I}^{12}$ to $1 \cdot 0 \times \mathrm{IO}^{13}$ particles/g nitrogen, whereas suspensions of trypsin-celite-purified $\mathrm{MRC}-4 \mathrm{f}$ contained $\mathrm{I} \times \mathrm{IO}^{13}$ to $3 \times 1 \mathrm{IO}^{13} \mathrm{particles} / \mathrm{g}$ 
nitrogen. Thus, in terms of nitrogen, immunopurified MRC-4f was less pure than other TRIC isolates for which there are data (Weiss et al. 1964; Wang et al. 1967; Detels et al. 1968). Nevertheless, considerable purification with respect to $E_{280}$ adsorbing (and presumably nitrogen poor) materials was achieved (Fig. 4).

The most probable sources of residual nitrogenous contamination were: egg antigens which had been specifically or non-specifically adsorbed and subsequently desorbed, or immunosorbent protein dissolved by the $\mathrm{pH}$ I ${ }^{\cdot} 3$ buffer. The nature of the contaminants in the immunopurified MRC-4f suspensions was investigated by guinea-pig hypersensitivity tests. Egg antigen was detected in five out of six samples (tested in guinea pigs sensitive to a minimum of $500 \mathrm{ng}$ of normal yolk sac antigens) whilst normal rabbit serum antigens (i.e. immunosorbent proteins) were detected in only one of the six samples tested $(<500 \mathrm{fg} /$ $\mathrm{ml}$ ). To confirm the presence of egg antigens, all desorbed samples were pooled, concentrated and used to immunize two rabbits following the schedule described in Methods for the production of anti-egg serum. Anti-egg antibodies were detected by immunodiffusion in the sera of both rabbits.

The egg antigens in the desorbed pools of MRC-4f might have come from non-specific adsorption of egg by the immunosorbent column or specific adsorption by the immunosorbent itself. The latter might have occurred if the serum from which the polymer was derived contained non-precipitating anti-egg antibodies undetected by immunodiffusion tests. [In this context, Nicklin \& Stephen (1974) demonstrated that non-precipitating antilysozyme antibody when polymerized in an immunosorbent was capable of adsorbing its homologous antigen and that the antigen could be subsequently desorbed.]

Purification of $M R C-4 f$, and other chlamydiae, using anti-TRIC immunosorbents derived from non-avid antisera raised to $M R C-4 f$ passaged three times through $\mathrm{HeLa}$ cells. Experiments were conducted with immunosorbent derived from a non-avid serum raised in rabbits by a single injection of thrice-passaged, HeLa cell-grown MRC-4f. Preliminary fractionation of crude homogenates of egg-grown MRC-4f on Sepharose $4 \mathrm{~B}$ was introduced to simplify the purification procedure. Three columns were prepared, each having a similar capacity for MRC-4f $\left(5 \times 10^{6}\right.$ to $12.5 \times 10^{6}$ particles $/ \mathrm{mg}$ immunosorbent protein). The yield of MRC-4f desorbed was similar for all columns and was approximately $33 \%$. The elution profile was similar to that in Fig. 4, the main difference being that the unadsorbed peak was more heterogenous, reflecting the nature of the starting material. Columns were re-cycled up to I I times without loss of capacity.

The adsorption and desorption of several chlamydiae using a single anti-MRC-4f immunosorbent column was investigated. Each of three strains of chlamydiae (MRC-4, gp-ic and Bour f) were grown in the yolk sac. The capacity of the immunosorbent for all three heterologous agents $\left(6 \times 10^{6}\right.$ to 1 I $\times 10^{6}$ particles $/ \mathrm{mg}$ immunosorbent protein $)$ was similar to that for the homologous agent (MRC-4f), and yields of desorbed gp-ic and Bour $\mathrm{f}$ were similar to those of desorbed MRC-4f. The recovery of strain MRC-4 on desorption was approximately $50 \%$ less than the yields for the others.

A suspension of immunopurified MRC-4f from one experiment contained $\mathrm{I} \cdot \mathrm{I} \times 10^{12}$ particles/g nitrogen but suspensions from others contained only I $\times 10^{11}$ to $3 \times 10^{11}$ particles $/ \mathrm{g}$ nitrogen. The samples were still contaminated with egg antigens whose presence could hardly be attributed to anti-egg antibodies in the serum from which the immunosorbent was derived. A considerable purification was again achieved with respect to $E_{280}$ absorbing materials but not in terms of nitrogen.

Adsorption of egg antigens by Sephadex G-I5 in immunosorbent columns. The previous experiment, together with the first experiment in this section, suggested that the egg antigens 
in the desorbed fractions of MRC-4f arose by non-specific adsorption by the Sephadex component of the immunosorbent column. This was tested by applying Sepharose-fractionated MRC-4f to a column of Sephadex G-I 5, washing with PBS and eluting with 0.2 Marginine- $\mathrm{HCl}$ buffer, $\mathrm{pH} \mathrm{II}_{1} \cdot 3$. Egg antigens were detected in both the unadsorbed and in the desorbed fractions. A similar result was obtained with a fresh column of Sephadex G-15. All the MRC-4f applied was recovered unadsorbed at neutral $\mathrm{pH}$.

Further attempts to purify immunosorbent-fractionated $M R C-4 f$. Since contamination of immunopurified MRC-4f with soluble egg antigens was attributable to Sephadex G-I5 (a necessary component in the construction of immunosorbent columns; Crook et al. 1972b), attempts were made to exploit Sephadex to purify MRC-4f further. A sample of immunopurified MRC-4f was passed through a column of Sephadex G-I 5 (equivalent to the volume of Sephadex in the immunosorbent column) equilibrated in PBS. Some of the egg antigens were adsorbed by the Sephadex but the remainder were recovered in the eluate, together with approximately $50 \%$ of the applied TRIC agent. The unadsorbed material was re-run on the same column after elution with $0.2 \mathrm{M}$-arginine- $\mathrm{HCl}$ buffer, $\mathrm{pH} \mathrm{II} \cdot 3$, and re-equilibration in PBS; it resolved again into an unadsorbed fraction (smaller than in the first cycle) containing egg antigens and no detectable TRIC, and a fraction which adsorbed to the Sephadex G-15. This approach was therefore abandoned.

Attempts were then made to remove egg antigens specifically using an anti-egg immunosorbent column derived from an avid anti-egg serum. Three adsorption-desorption cycles were performed with immunopurified MRC-4f. The unadsorbed PBS eluate never contained any MRC-4f and had only slight $280 \mathrm{~nm}$ absorption. No MRC-4f was detected in the neutral desorbed fraction when the anti-egg immunosorbent was eluted with $0.2 \mathrm{M}$-arginine- $\mathrm{HCl}$ buffer, $\mathrm{pH}$ I I 3 . Two adsorption-desorption cycles were then performed using two separately prepared batches of trypsin-celite-fractionated MRC-4f. With each, a high percentage of the applied MRC-4f was adsorbed by the anti-egg immunosorbent but a small quantity (Io and $21 \%$, respectively) of MRC-4f was recovered unadsorbed in the PBS eluate. These results suggested that some egg antigens were closely associated with TRIC particles and were responsible for binding particles to the anti-egg immunosorbent. Recovery of some particles - derived by partial purification of egg-grown TRIC by the trypsin-celite procedure - unadsorbed by anti-egg immunosorbent suggested that the particle-associated egg antigen might be removed by treatment of the organisms with an appropriate enzyme.

\section{Purification of MRC-4 fusing phospholipase C}

Since treatment of MRC-4f with trypsin might have removed particle-associated egg antigens, further (but only partially successful) studies with this enzyme were made. The effect of phospholipase was also examined because of the probable nature of the contaminants. Phospholipid contents and dry weights were used as additional criteria of purity.

Purification of MRC-4f with crude phospholipase C. Modified $\mathrm{KCl}$-fractionated MRC-4f $\left(4.5 \times 10^{9}\right.$ particles $\left./ \mathrm{ml}\right)$ was treated with crude Clostridium welchii culture filtrate $(\mathrm{I} .6 \mathrm{mg} / \mathrm{ml}$, ${ }_{25} \mathrm{LV}$ units phospholipase $\mathrm{C} / \mathrm{ml}$ ). Samples were taken after 5, I5, 60 and $\mathrm{I} 20$ min incubation, stored, filtered, centifuged, resuspended and analysed. The most rapid change in particle to nitrogen, lipid phosphorus or dry weight ratios occurred within Io min of incubation (Fig. 5); the experiment was stopped at $2 \mathrm{~h}$. Whilst enzyme treatment gave only a $2 \cdot 2$-fold increase in purity as measured by total nitrogen, $3 \cdot 6$-fold and $6 \cdot 6$-fold purifications were achieved in terms of lipid phosphorus and dry weight, respectively. From the nitrogen measurements, the suspension of MRC-4f was approximately tenfold more pure than preparations of 
MRC-4f purified by the trypsin-celite procedure. Guinea-pig hypersensitivity tests did not detect egg antigens in the suspension of MRC-4f treated with enzyme for $2 \mathrm{~h}$. The recovery of TRIC particles at the modified KCl-fractionation stage was $46 \%$ of the original crude homogenate and the overall recovery after all subsequent treatments was $45 \%$, i.e. little loss was sustained from the modified $\mathrm{KCl}$-fractionation stage to the final product.

In four experiments in which separate suspensions of $\mathrm{MRC}-4 \mathrm{f}$ were treated with crude Cl. welchii culture filtrate ( $25 \mathrm{LV}$ units phospholipase $\mathrm{C} / \mathrm{ml}, 2 \mathrm{~h}$ at $37^{\circ} \mathrm{C}$ ), the increases in purity achieved were approximately twofold by total nitrogen measurements (mean $6.6 \times 10^{13}$ particles/g nitrogen) and 3.8-fold by total lipid phosphorus (mean $1 \cdot 6 \times 10^{15}$ particles/g lipid phosphorus).

Purification of $M R C-4 f$ with pure $C l$. welchii phospholipase $C$. To confirm that, of the large number of enzymes known to be present in the crude $\mathrm{Cl}$. welchii culture filtrate, the phospholipase $\mathrm{C}$ was the enzyme responsible for the observed purification of MRC- $4 \mathrm{f}$, a sample of phospholipase was purified from the culture filtrate by immunosorbent fractionation (Bird et al. 1974). A batch of modified KCl-fractionated MRC-4f ( $\left.3 \times 10^{9} \mathrm{particles} / \mathrm{ml}\right)$ was treated with purified enzyme ( 13 units phospholipase $\mathrm{C} / \mathrm{ml}$ ) using the method described above, except that the time of incubation was restricted to $60 \mathrm{~min}$ because of the known thermal lability of the purified enzyme. The purified suspension of MRC-4f contained $5.8 \times 10^{13}$ particles/g nitrogen and $8.7 \times 10^{14}$ particles/g lipid phosphorus. The degree of purification achieved was similar to that recorded above.

Attempts to detect contaminating egg antigens in phospholipase C-purified $M R C$ - $4 f$ using anti-egg immunosorbents. Anti-egg immunosorbent was used to determine whether treatment of suspensions of yolk sac-grown MRC-4f with phospholipase $\mathrm{C}$ had removed egg antigen complexes from the TRIC particles. This technique was employed since it was predicted that 'egg-free particles' should not be adsorbed. Moreover, a batch process was used to overcome the adsorptive effects of Sephadex G-I 5. Phospholipase C-treated MRC-4f was compared with $\mathrm{KCl}$-fractionated $\mathrm{MRC}-4 \mathrm{f}$. Each suspension was divided into three parts and added to $5 \mathrm{mg}$ quantities of three polymers: an avid anti-egg immunosorbent, a non-avid anti-MRC-4f immunosorbent (from serum raised to thrice passaged-HeLa cell-grown MRC-4f) and a polymer derived from unrelated $\gamma$-globulin; the latter had previously been shown not to react with normal yolk sac antigens in immunodiffusion tests. $\mathrm{KCl}$-fractionated $\mathrm{MRC}-4 \mathrm{f}$ behaved as predicted: there was no retention of the TRIC particles by the unrelated $\gamma$-globulin polymer; the anti-MRC-4f immunosorbent exhibited its expected capacity for the homologous agent $\left(8 \times 10^{6}\right.$ particles/mg polymer protein); MRC-4f particles were adsorbed to the anti-egg immunosorbent.

The suspension of MRC-4f purified by phospholipase $\mathrm{C}$ did not behave as predicted for there was non-specific adsorption of the enzyme-purified MRC-4f to the unrelated $\gamma$ globulin polymer; this had not previously been detected. The anti-MRC-4f immunosorbent adsorbed the predicted amount of agent; some TRIC particles were also adsorbed by the anti-egg immunosorbent. In a second experiment, phospholipase C-purified MRC-4f was pretreated with egg antigens; the latter were derived from the supernatant from the first high-speed centrifugation in the preparation of modified $\mathrm{KCl}$-fractionated $\mathrm{MRC}-4 \mathrm{f}$. The rationale here was to convert the phospholipase $\mathrm{C}$-treated particles to the form in which they were not adsorbed. Such pretreatment caused partial inhibition of the non-specific adsorption of the TRIC particles by unrelated polymers: only $45 \%$ of the applied load was adsorbed by $5 \mathrm{mg}$ of polymer compared with $85 \%$ of phospholipase C-purified MRC-4f adsorbed when not pretreated with egg antigens. The kinetics of adsorption of phospholipase C-treated MRC-4f by its homologous anti-MRC-4f immunosorbent and by the polymer 
derived from unrelated $\gamma$-globulin did not distinguish between the rates of specific and non-specific adsorption, although the former might be predicted to be more rapid.

Effect of phospholipase $C$ treatment on the viability of $M R C-4 f$. In two experiments, phospholipase $\mathrm{C}$ treatment gave a I00-fold drop in infectivity (measured in HeLa cells) of MRC-4f below that of the modified $\mathrm{KCl}$-fractionation stage. This loss occurred in two stages: a tenfold loss during incubation at $37^{\circ} \mathrm{C}$ for $2 \mathrm{~h}$, and a further tenfold loss after over-night standing, filtration and centrifugation. In an attempt to reduce the loss of infectivity, the conditions of phospholipase treatment were altered. The ionic strength (approximately 0.5 ) of the borate buffer saline was reduced by half (but without changing the concentration of calcium chloride $-0.05 \%, \mathrm{w} / \mathrm{v}$ ) and the tonicity of the buffer was increased by the addition of 0.25 -M-sucrose. The concentration 'of enzyme was increased fourfold and the time of incubation at $37^{\circ} \mathrm{C}$ reduced to $30 \mathrm{~min}$. Under these conditions, a quantity of modified $\mathrm{KCl}$-fractionated $\mathrm{MRC}-4 \mathrm{f}$ was treated with crude phospholipase $\mathrm{C}$ and immediately filtered, centrifuged and assayed. There was no significant inactivation of the particles arising from this purification procedure. The final product contained $5.7 \times 10^{13}$ particles $/ g$ nitrogen and $1 \cdot 5 \times 10^{15}$ particles $/ g$ lipid phosphorus.

\section{DISCUSSION}

The main objective of this work was to apply immunosorbent technology to purify yolk sac-grown MRC-4f. A column procedure was developed, resulting in considerable - but not complete - purification of the organisms with full retention of infectivity. The enzymic and serological studies, together with the adsorption properties of the purified particles, indicated that the principal contaminants in preparations of immunopurified MRC- $4 \mathrm{f}$ were soluble and particle-associated phospholipid-containing antigens.

The experiments also provided information on the mechanism of antigen desorption and the interactions of phospholipids in these disulphide-linked immunosorbent systems. Detailed arguments have been presented elsewhere (Crook et al. $1972 b$ ) for the view that successful desorption of homologous antigen with buffers of extreme $\mathrm{pH}$ depends on a rapid rate of protonation (or alternatively, hydroxylation) of the antigen and its rapid return to neutral conditions. In practice this is achieved when the desorbing buffer front elutes as a sharp pH-gradient and the immunosorbent column is appropriately constructed with suitable molecular exclusion material such as Sephadex G-I5. This work provides direct evidence that the period of contact between bound antigen and desorbing buffer must be short: infective particles were recovered using as desorbent a buffer which destroyed the particles in suspension.

Consideration of the interactions of phospholipids will be restricted to those present in semi-purified preparations. Specific adsorption of TRIC particles by homologous immunosorbent is in part dependent on an egg-derived phospholipid fraction associated with the particles. It cannot cover the whole surface, otherwise no TRIC-specific adsorption would have been possible. Removal of this material with phospholipase $\mathrm{C}$ removes the specificity of particle uptake by -S-S-linked immunosorbents. It is not clear whether the phospholipid prevents non-specific adsorption by altering the properties of the particles per se or by excess of such material saturating non-specific binding sites on the polymer.

The interaction of soluble phospholipids with Sephadex G-I 5 also proved important and caused contamination of immunopurified MRC-4f particles. These substances were adsorbed by the Sephadex G-15 component of immunosorbent columns and desorbed by the alkaline buffer used to desorb TRIC particles from -S-S-linked antibody. The presence of phospho- 
lipid prevented the adsorption of TRIC particles by Sephadex G-I5 on its own, whereas the absence of phospholipid allowed this. It appears, therefore, that to exploit fully a twostep, immunospecific fractionation system for isolating infective TRIC (or other chlamydiae) from the complex lipid-rich mixture that comprises yolk sac homogenates, a substitute for Sephadex G-1 5 must be found. This should possess the molecular exclusion properties of Sephadex G-15, and should not adsorb phospholipid materials or 'clean' TRIC particle at neutral pH. However, it is unlikely that such improvements would succeed in removing particle-associated host contaminants; the latter may best be removed by chemical or, as here, by enzymic methods. The most highly purified preparations of chlamydiae were either obtained from sources other than yolk sac (Jenkin, 1960; Garrett, Harrison \& Manire, 1974), or purified by methods which include chemical (Wang et al. 1967) or enzymic (Weiss et al. 1964) treatments.

The experiments with phospholipase $\mathrm{C}$ suggest a new approach to obtaining good yields of egg-grown chlamydiae which retain infectivity. However, relatively less pure preparations of modified $\mathrm{KCl}$-fractionated $\mathrm{MRC}-4 \mathrm{f}$ yielded relatively less pure preparations of $\mathrm{MRC}-4 \mathrm{f}$ (by the criteria of nitrogen and lipid phosphorus) after treatment with phospholipase $\mathrm{C}$. The most probable explanation for the variations observed in the purity of the final product is that the standard conditions of enzyme treatment - concentration of enzyme in relation to the available substrate, present both as free and particle-associated phospholipid, and the time of incubation - were too varied to yield reproducible results. A second explanation is that the method for separating the purified particles from the gel-like aggregates was not good enough. A third possibility is that the differences in the purity of the suspensions of modified $\mathrm{KCl}$-fractionated $\mathrm{MRC}-4 \mathrm{f}$ are due to differing degrees of contamination with substances other than phospholipid.

Viable TRIC particles were obtained with the highest measured particle:g nitrogen ratio ever reported for yolk sac-grown agent. Purities were measured as particle:phospholipid (lipid phosphorus) ratios. Reproducible retention of infectivity is clearly a function of optimizing conditions for enzyme treatment and removal of the gel-like aggregates which form as a result. An additional point arising from these studies is that the enzyme may remove a particle-specific component without affecting infectivity. Gogolak \& Ross (1955) and Ross \& Gogolak (1957) reported a phospholipid (lecithin) as part of the chlamydial group-specific complement-fixing antigen. Analysing highly purified suspensions of allantoicgrown meningopneumonitis agent, Jenkin (1960) also detected phospholipid in the chlamydial particle. Thus the effect of enzyme treatment on the group antigen must be investigated, especially because there is no information about the role of the group-specific complementfixing antigen in infectivity. It would be interesting to examine organisms treated with phospholipase $\mathbf{C}$, with their apparently altered surface properties, in the biological system of Woodland, Griffiths \& Pearce (1973) who are investigating adherence phenomena as the possible basis of specificity in chlamydial infections.

Finally, in immunodiffusion tests, seven TRIC-specific precipitins were detected in avid sera. This is similar to the results of Katzenelson \& Bernkopf (1967) and Kuo, Kenny \& Wang (197I). Immunodiffusion analysis indicated three common antigens in $\mathrm{MRC}-4 \mathrm{f}$ (Chlamydia trachomatis) and gp-ic (Chl. psittaci). Kuo et al. (197I) suggested three antigens are common to members of the genus. There was no apparent difference between the two $f$ variants tested, MRC-4f and Bour f, but MRC-4f could be distinguished from its parent MRC-4. Because of these antigenic similarities, all four agents tested could be 'purified' on a single (anti-MRC-4f) immunosorbent column. Non-avid anti-MRC-4f antisera usually showed fewer precipitins in immunodiffusion tests. 
After this manuscript had been submitted, our attention was drawn to the work of Howard, Orenstein \& King (1974), who purified Chl. trachomatis from egg yolk sacs by centrifugation on Renografin density gradients. The purity of their final prepartions was $5.7 \times 10^{12}$ to $7.0 \times 10^{12}$ particles/g dry weight and $7.8 \times 10^{12}$ to $9.7 \times 10^{12}$ particles $/ g$ protein. These are not so good as the best data in this paper but we think that this technique could be valuable as a first-stage purification step.

The Wellcome Foundation generously supported this work. Particular thanks are due to Dr J. H. Pearce and colleagues (Department of Microbiology, University of Birmingham) for guidance in handling and assaying chlamydiae, Dr R. O. Thomson and Dr M. Hughes (Wellcome Research Laboratories) for performing hypersensitivity assays, and to Professor H. Smith (Department of Microbiology, University of Birmingham), Dr A. J. Beale and Dr N. B. Finter (Wellcome Research Laboratories) for many fruitful discussions.

\section{REFERENCES}

BARTLETT, G. R. (1959). Phosphorus assay in column chromatography. Journal of Biological Chemistry 234, 466-468.

Bird, R. A., Low, M. G. \& Stephen, J. (1974). Immunopurification of phospholipase C ( $\alpha$-toxin) from Clostridium perfringens. FEBS Letters 44, 279-28I.

BIRKBECK, T. H. \& STEPHEN, J. (1970). Specific removal of host-cell or vaccinia-virus antigens from extracts of infected cells by polyvalent disulphide-linked immunosorbents. Journal of General Virology 8, 133-142.

BIRKBECK, T. H. \& STEPHEN, J. (197I). Immunochemical isolation of vaccinia virus antigens. Immunochemistry 8, 1029-1039.

BLIGH, E. G. \& Dyer, W. J. (1959). A rapid method of total lipid extraction and purification. Canadian Journal of Biochemistry and Physiology 37, $91 \mathrm{I}-917$.

Chidlow, J. W., Stephen, J. \& SMith, H. (1970). Further studies on the specific and quantitative aspects of antigen adsorption by disulphide-linked antibody immunosorbents. Immunochemistry 7, 505-5I4.

Collier, L. H. (1972). Some aspects of trachoma control and provisional estimates of the cost of vaccine production. Israel Journal of Medical Sciences 8, I I $14-1123$.

Colón, J. I. \& Mouldor, J. W. (1958). Folic acid in purified preparations of members of the psittacosis group of micro-organisms. Journal of Infectious Diseases 103, I09-I 19.

Crook, N. E., Chrdlow, J. W., StePhen, J. \& SMith, H. (1972a). Improved methods for the production of disulphide-linked antibody immunsorbents. Immunochemistry 9, 749-752.

Crook, N. E., Stephen, J. \& SMith, H. (1972b). Recovery of bound homologous protein antigens from disulphide-linked immunsorbents at neutral pH. Immunochemistry 9, 945-960.

Crowle, A. J. (1958). A simplified micro double diffusion agar precipitin technique. Journal of Laboratory and Clinical Medicine 52, 784-787.

Detels, R., WANG, S. P. \& Grayston, J. T. (1968). Febrile and local reactions to two highly concentrated trachoma vaccines with and without adjuvant. Revue internationale du trachome 45, 33I-340.

Dulbecco, R. \& VoGt, M. (1954). Plaque formation and isolation of pure lines with poliomyelitis virus. Journal of Experimental Medicine 99, 167-182.

Garrett, A. J., Harrison, M. J. \& MANire, G. P. (1974). A search for the bacterial mucopeptide component, muramic acid, in Chlamydia. Journal of General Microbiology 80, 315-318.

GoGolak, F. M. \& Ross, M. R. (1955). The properties and chemical nature of the psittacosis virus haemagglutinin. Virology $1,474-496$.

Hanna, L., Thygeson, P., Jawetz, E. \& Dawson, C. (1959). Elementary body virus isolated from clinical trachoma in California. Science, New York 130, 1339-1 340.

Howard, L., Orenstein, N. S. \& KING, N. W. (1974). Purification on Renografin density gradients of Chlamydia trachomatis grown in the yolk sac of eggs. Applied Microbiology 27, 102-106.

Hughes, M., Thomson, R. O., KNight, P. \& StePhen, J. (I974). The immunopurification of tetanus toxin. Journal of Applied Bacteriology 37, 603-621.

JeNKIN, H. M. (1960). Preparation and properties of cell walls of the agent of meningopneumonitis. Journal of Bacteriology 80, 639-647. 
JoNEs, B. R. (196I). Trachoma and allied infections, opening paper. Transactions of the Ophthalmological Society of the United Kingdom 8r, 367-378.

KATZENELSON, E. \& BeRNKOPF, H. (1965). Serological differentiation of trachoma strains and other agents of the psittacosis-lymphogranuloma venereum-trachoma group with the aid of the direct fluorescent antibody method. Journal of Immunology 94, 467-474.

KATZenelson, E. \& BeRnKOPF, H. (1967). Studies of PLT agents with the aid of the agar immune diffusion technique. American Journal of Ophthalmology 63, I483-1487.

Kuo, C. C., KenNY, G. E. \& WANG, S. P. (I97I). Trachoma and psittacosis antigens in agar gel double immunodiffusion. In Trachoma and Related Disorders Caused by Chlamydial Agents. Proceedings of a Symposium held in Boston, Massachusetts, pp. I 13-123. Edited by R. L. Nichols. Amsterdam: Excerpta Medica.

Miller, G. L. \& Golder, R. H. (1950). Buffers of pH 2 to 12 for use in electrophoresis. Archives of Biochemistry 29, 420-423.

Moulder, J. W. \& Weiss, E. (195I). Purification and properties of the agent of feline pneumonitis. Journal of Infectious Diseases 88, 56-67.

MURRAY, E. S. (1964). Guinea pig inclusion conjunctivitis virus. I. Isolation and identification as a member of the psittacosis-lymphogranuloma-trachoma group. Journal of Infectious Diseases 114, I-I2.

NiCKLIN, M. G. \& STEPHEN, J. (1973). Solubilities of protein-antigen/rabbit-antibody complexes as a measure of serum avidity. Immunochemistry 10, 717-725.

NickLIN, M. G. \& STEPHEN, J. (1974). Recovery of protein antigens from disulphide-linked immunosorbents derived from non-avid sera. Immunochemistry II, 35-40.

Ormsbee, R. A. \& Weiss, E. (1963). Trachoma agent: glucose utilisation by purified suspensions. Science, New York $\mathrm{x42}, 1077-1078$.

Provost, P. J. \& VICKers, J. H. (1972). Attempted immunization against trachoma infection in baboons. American Journal of Veterinary Research 33, 599-605.

ReEVE, P. \& TAVERNE, J. (1962). A simple method for total particle counts of trachoma and inclusion blennorrhoea viruses. Nature, London 195, 923-924.

ReEVE, P. \& TAVERNE, J. (1967). Strain differences in the behaviour of TRIC agents in cell cultures. American Journal of Ophthalmology 63, I167-I 173.

Ross, M. R. \& GoGolaK, F. M. (1957). The antigenic structure of psittacosis and feline pneumonitis viruses. I. Isolation of complement-fixing antigens with group and species specificity. Virology 3, 343-364.

SAROV, I. \& BeCKER, Y. (1968). RNA in the elementary bodies of trachoma agent. Nature, London 217, 849-852.

Smith, H., Tozer, B. T., Gallop, R. C. \& Scanes, F. S. (1962). Separation of antigens by immunological specificity. I. Method for separating individual antigen-antibody complexes from mixed antigens and antibodies. Biochemical Journal 84, 74-80.

Sowa, S., Sowa, J., Collier, L. H. \& Blyth, W. A. (1969). Trachoma vaccine field trials in the Gambia. Journal of Hygiene 67, 699-717.

Stephen, J., Gallop, R. G. C. \& SMith, H. (1966). Separation of antigens by immunological specificity. Use of disulphide-linked antibodies as immunosorbents. Biochemical Journal ror, 71 7-720.

Sweet, C., StePhen, J. \& SMith, H. (1974). Purification of influenza viruses using disulphide-linked immunosorbents derived from rabbit antibody. Immunochemistry II, 295-304.

Tamura, A. \& Higashi, N. (1963). Purification and chemical composition of meningopneumonitis virus. Virology 20, 596-604.

Tang, F. F., Chang, H. L., Huang, Y. T. \& Wang, K. C. (1957). Studies on the etiology of trachoma with special reference to isolation of the virus in chick embryo. Chinese Medical Journal (Peking) 75, 429-446.

TAVERNE, J., BLyTH, W. A. \& ReEVE, P. (1964). Toxicity of the agents of trachoma and inclusion conjunctivitis. Journal of General Microbiology 37, $271-275$.

Vedros, N. A. (1967). Species-specific antigens from trachoma and inclusion conjunctivitis (chlamydial) agents. Journal of Immunology 99, I $183-1186$.

WANG, S. P. \& GraYston, J. T. (1967). A potency test for trachoma vaccine utilizing the mouse toxicity prevention test. American Journal of Ophthalmology 63, I443-I454.

WANG, S. P., KenNY, G. E. \& Grayston, J. T. (1967). Characterisation of trachoma antigens protective against mouse toxicity. American Journal of Ophthalmology 63, I454-1461.

Watson, D. H. \& WiLdY, P. (1969). The preparation of 'monoprecipitin' antisera to herpes virus specific antigens. Journal of General Virology 4, 163-168. 
Weiss, E., Myers, W. F., Dressler, H. R. \& Chun-Hoon, H. (1964). Glucose metabolism by agents of the psittacosis-trachoma group. Virology 22, 55I-562.

Weiss, E., Schramek, S., Wilson, N. N. \& Newman, L. W. (1970). Deoxyribonucleic acid heterogeneity between human and murine strains of Chlamydia trachomatis. Infection and Immunity 2, 24-28.

Wood, K. R., GouLd, E. A. \& SMItH, H. (1970). Purification of Semliki Forest virus using disulphide-linked immunosorbents derived from rabbit or fowl antibody. Journal of General Virology 6, 257-265.

WOOD, K. R., STEPHEN, J. \& SMITH, H. (1968). Specific adsorption of Semliki Forest virus on a disulphidelinked immunosorbent derived from rabbit antibody. Journal of General Virology 2, 313-316.

Woodland, R. M., Griffiths, M. S. \& Pearce, J. H. (1973). Adherence and specificity in chlamydial infections. Proceedings of the Society for General Microbiology I, 27. 